\title{
Density derived estimates of standing crop and net primary production in the giant kelp Macrocystis pyrifera
}

\author{
Daniel Reed · Andrew Rassweiler $\cdot$ Katie Arkema
}

Received: 22 April 2009/ Accepted: 16 June 2009/Published online: 28 June 2009

(C) The Author(s) 2009. This article is published with open access at Springerlink.com

\begin{abstract}
Assemblages of macroalgae are believe to be among the most productive ecosystems in the world, yet difficulties in obtaining direct estimates of biomass and primary production have led to few macroalgal data sets from which the consequences of long-term change can be assessed. We evaluated the validity of using two easily measured population variables (frond density and plant density) to estimate the more difficult to measure variables of standing crop and net primary production (NPP) in the giant kelp Macrocystis pyrifera off southern California. Standing crop was much more strongly correlated to frond density than to plant density. Frond density data collected in summer were particularly useful for estimating annual NPP, explaining nearly $80 \%$ of the variation in the NPP from year to year. Data on frond densities also provided a relatively good estimate of seasonal NPP for the season that the data were collected. In contrast, estimates of seasonal and annual NPP derived from plant density data were less reliable. These results indicate that data on frond density collected at the proper time of year can make assessments of NPP by giant kelp more tractable. They also suggest that other easily measured variables that are strongly correlated with standing crop, such as surface canopy area, might serve as similarly useful proxies of NPP.
\end{abstract}

Communicated by U. Sommer.

D. Reed $(\bowtie) \cdot$ A. Rassweiler

Marine Science Institute, University of California,

Santa Barbara, CA 93106, USA

e-mail: reed@lifesci.ucsb.edu

K. Arkema

Woods Institute for the Environment, Stanford University,

Stanford, CA 94305, USA

\section{Introduction}

The rate at which organic matter is produced per unit area of the earth's surface (commonly referred to as net primary production or NPP) influences virtually all ecological processes. Not surprisingly, there is growing interest and concern regarding the extent to which patterns of NPP are being altered by global and regional climate change (Melillo et al. 1993; Schneider et al. 2008). These interests and concerns aptly apply to marine macroalgae whose assemblages in shallow coastal waters form some of the most productive ecosystems in the world (Mann 1973). Unfortunately, there are very few data sets of spatial and temporal patterns of macroalgal biomass and NPP from which the consequences of long-term change can be assessed and compared. The bulk of information on seaweed biomass and production to date has come from shortterm studies done over small spatial scales using a wide variety of methods that frequently measure different attributes. Consequently, estimates of standing biomass and NPP for macroalgae are as numerous and variable as the methods that have been devised to measure them (Alongi 1998).

One explanation for the paucity of time series data on seaweed biomass and NPP is that these variables tend to be difficult to measure on an ongoing basis, particularly in the intertidal and sublittoral zones of wave swept shores where macroalgal biomass and productivity tend to be highest (Leigh et al. 1987; Mann 2000). Time series data on standing crop and NPP are best obtained using nondestructive methods, which typically are very time consuming to employ even in the most favorable working conditions. Suffice to say that our understanding of patterns, causes, and ecological consequences of change in macroalgal biomass and productivity would benefit greatly 
from the development of easily measured indicators that could be used to accurately estimate macroalgal standing crop and NPP on both an annual and seasonal basis.

Here, we use a unique 6-year data set from southern California consisting of monthly measurements of frond density, plant density, foliar standing crop and NPP in the giant kelp Macrocystis pyrifera, to examine how two easily measured population variables, frond density and plant density, correlate with the more difficult to measure variables of foliar standing crop and NPP.

Macrocystis pyrifera is the world's largest alga and it forms lush forests in temperate seas of the Pacific and Southern Oceans (Graham et al. 2007). As with all kelps, M. pyrifera has a heteromorphic life history that includes free-living microscopic and macroscopic stages. The large macroscopic stage of $M$. pyrifera (hereafter referred to as a plant for convenience) is made up of a bundle of fronds (often totaling more than 100 in California) anchored by a common holdfast. New fronds originate in the basal foliage just above the holdfast, grow vertically in the water column, and form a dense canopy at the sea surface. Densities of plants and fronds are among the most commonly measured variables in population studies of $M$. pyrifera, particularly those studies that have investigated patterns and causes of temporal population change over the long-term (e.g., Dayton et al. 1999; Edwards 2004). Our intent was to evaluate the possibility of using data on the density of $M$. pyrifera plants and fronds to estimate foliar standing crop and NPP, and to determine how the accuracy of these estimates vary depending on the time of year data are collected. Because many short-term ecological studies may benefit from information on how to estimate NPP by $M$. pyrifera over shorter time scales, we examined the utility of density data in estimating NPP on a seasonal basis as well.

\section{Materials and methods}

Data for this study were collected from January 2003 through December 2008 at three giant kelp forests located off the coast of Santa Barbara California, USA: Mohawk Reef $\left(34^{\circ} 23.660^{\prime} \mathrm{N}, \quad 119^{\circ} 43.800^{\prime} \mathrm{W}\right)$, Arroyo Burro $\left(34^{\circ} 24.007^{\prime} \mathrm{N}, 119^{\prime} 44.663^{\prime} \mathrm{W}\right)$, and Arroyo Quemado $\left(34^{\circ} 28.127^{\prime} \mathrm{N}, 120^{\circ} 07.285^{\prime} \mathrm{W}\right)$. These forests occur on low relief bedrock reefs whose dimensions range from $\sim 300 \mathrm{~m}$ (Mohawk and Arroyo Burro) to 1,500 m (Arroyo Quemado) in length (alongshore dimension) and $\sim 200-300 \mathrm{~m}$ in width (cross-shore dimension). The data and the methods used to calculate standing crop and NPP are described in detail elsewhere (Rassweiler et al. 2008) and summarized below.

Data on M. pyrifera were collected monthly (i.e., 71 out of 72 months) in a permanent plot at each of the three study sites. Plots were located at 6-8 m depth and were $200 \mathrm{~m}^{2}$ in area at Arroyo Quemado and Mohawk and $480 \mathrm{~m}^{2}$ at Arroyo Burro. All M. pyrifera plants $>1 \mathrm{~m}$ tall in each plot were counted and measured on each sampling date to determine the densities of plants and fronds at each site ( $N=19,607$ plants counted and measured during the study period). To estimate foliar standing crop (hereafter FSC, which we define as the standing biomass minus the mass associated with holdfasts and reproductive blades termed sporophylls) we characterized each plant as consisting of three distinct sections: (1) the "subsurface" section consisted of fronds that did not reach the surface, (2) the "water column" section was the subsurface portion of fronds that reached the surface, and (3) the "canopy" section was the portion of the fronds at the sea surface. For each plant within the permanent plots we counted the number of fronds $1 \mathrm{~m}$ above the holdfast $\left(N_{1 \mathrm{~m}}\right)$ and the number of fronds at the surface ( $N_{\text {surface}}$ ), and we measured the water depth at the top of the holdfast $(D)$ and the length of the canopy portion of the longest frond (MAX). We used these measurements to calculate the combined length of all fronds in each plant section according to the following equations:

subsurface length $=\left(N_{1 \mathrm{~m}}-N_{\text {surface }}\right)(1+1 / 2[D-1])$

water column length $=\left(N_{\text {surface }}\right)(D)$

canopy length $=\left(N_{\text {surface }}\right)(1 / 2 \max )$

The lengths of the three plant sections were summed to obtain the total length of each plant.

We tested the accuracy of Eqs. 1, 2, and 3 in estimating the total frond length by comparing estimates of length obtained using these equations to actual lengths of adult $M$. pyrifera collected monthly from each of the three sites during the period June 2002-June 2003 ( $N=55$ plants). We measured the length of all fronds on each plant collected from the field and compared the sum of these lengths to the total frond length obtained by summing the values given by Eqs. 1, 2 and 3. Total frond length estimated using Eqs. 1, 2, and 3 was an excellent predictor of actual total frond length $\left(r^{2}=0.993\right.$, slope $\left.=1.02\right)$.

Total length was converted into total mass using relationships generated from length and weight measurements of the 55 adult $M$. pyrifera collected from the field [the ratios of frond wet mass $(\mathrm{kg})$ to frond length $(\mathrm{m})$ were $0.117,0.105$ and 0.259 for the subsurface, water column, and canopy sections, respectively]. The wet mass of each plant was converted to dry mass based on the average moisture content of blades collected haphazardly from 10 to 15 plants at each site during each monthly survey. Data on plant mass were used to calculate site-specific values for M. pyrifera FSC in units of dry $\mathrm{kg} \mathrm{m}^{-2}$ for each monthly sample period. 
Net primary production by $M$. pyrifera at each site was calculated from field measurements of FSC and a simple model of kelp dynamics (see below) that assumed the biomass within a sampling period was produced and lost at rates proportional to the existing standing crop. Using this model we calculated monthly values of NPP and specific growth rate (i.e., the rate at which new kelp tissue is produced per unit of existing kelp tissue) that accounted for the observed change in standing crop given independently measured loss rates. Independent estimates of instantaneous loss rates of entire plants and of fronds on surviving plants were obtained each month from 10 to 15 tagged plants at each site. Loss rates of plants were based on the fraction of tagged plants that survived from one sampling date to the next; loss rates of fronds were based on the fraction of surviving tagged fronds on surviving tagged plants.

Using our estimates of the standing crop at the beginning and end of each sampling interval $\left(S_{0}, S_{t}\right)$ and the loss rate $(l)$ during the sampling interval we calculated the average growth rate $g$ of $M$. pyrifera as

$g=\frac{1}{T} \ln \left(\frac{S_{t}}{S_{0}}\right)+l$

where $T$ is the number of days in the sampling interval. This exponential model implies that NPP at any moment is the product of $g$ and $S$. By assuming that growth and loss rates are constant over the period and expressing $S$ at any time $t$ as a function of the standing crop at the beginning of the sampling interval, growth rate, and loss rate $\left(S_{t}=S_{0} e^{(g-l) t}\right)$, we estimated daily NPP for each sampling interval by integrating instantaneous NPP over the interval and dividing by $T$

$\mathrm{NPP}=\int_{0}^{T} g S_{t} \mathrm{~d} t$

NPP was expressed as daily rates to account for slight variations in the length of the sampling intervals. Our field measurements of FSC and loss rate enabled us to calculate the average NPP by $M$. pyrifera on seasonal and annual time scales; limitations of the sampling methodology render our data less appropriate for examining patterns of NPP over shorter time scales. Mean daily NPP for each astronomical season (i.e., winter, spring, summer, and autumn as bounded by the winter solstice, spring equinox, summer solstice, and autumnal equinox) was calculated as the mean NPP averaged over all days in the season. Annual NPP for a given year was calculated as the daily NPP summed over all days in the year.

The above data on $M$. pyrifera were used in linear regressions to examine the strength of the following relationships: (1) frond density in a given month versus mean daily NPP during the season represented by that month, (2) plant density in a given month versus mean daily NPP during the season represented by that month, (3) frond density in a given month versus the annual NPP for the year, and (4) plant density in a given month versus the annual NPP for the year. The $y$-intercepts for NPP in linear equations derived from these regressions were rounded to the nearest gram. Linear functions were chosen because they explained similar or greater amounts of variation than exponential or quadratic functions for all relationships. Because we were specifically interested in predicting NPP from plant and frond density we employed Model I regressions as per the recommendations of Sokal and Rholf (1995) and Legendre and Legendre (1998). One way ANOVAs were used to test whether the densities of plants and fronds differed for different months of the year.

\section{Results}

The density of $M$. pyrifera plants and fronds $>1 \mathrm{~m}$ tall varied significantly throughout the year $\left(F_{11,197}=3.76\right.$, $P<0.001$ for plants, $F_{11,197}=3.23, \quad P<0.001$ for fronds). Both plants and fronds were generally at their lowest densities in March, which typically marks the end of winter storm season in California (Fig. 1a, b). The abundance of plants increased dramatically in late spring and summer reaching peak densities in September before steadily declining through December. In contrast, the average density of fronds increased steadily from March to December. Average plant size (as indicated by the mean number of fronds per plant) was greatest in winter and spring when plant densities were lowest (Fig. 1c). The recruitment of small young plants in spring and summer led to the rapid increase in plant densities (Fig. 1a) and a concomitant decrease in plant size (Fig. 1c). The more gradual increase seen in frond densities in spring and summer (Fig. 1b) reflected the steady initiation of new fronds on plants that survived the winter as well as the recruitment and growth of new plants. The abrupt decline in the densities of plants and fronds observed between December and January resulted from losses incurred during the first winter storms (see Reed et al. 2008).

The seasonality displayed in the densities of $M$. pyrifera plants and fronds produced similar seasonal trends in FSC and NPP. Standing crop was generally lowest in winter and spring, intermediate in summer, and highest in autumn (Fig. 1d), whereas NPP was lowest in winter and spring, intermediate in autumn, and highest in summer (Fig. 1e).

Not surprisingly, FSC was positively related to densities of both plants and fronds $\left(F_{1,207}=108, P<0.0001\right.$ for plants in Fig. $2 \mathrm{a}$, and $F_{1,207}=758, P<0.0001$ for fronds in Fig. 2b). However, the density of fronds proved to be a 

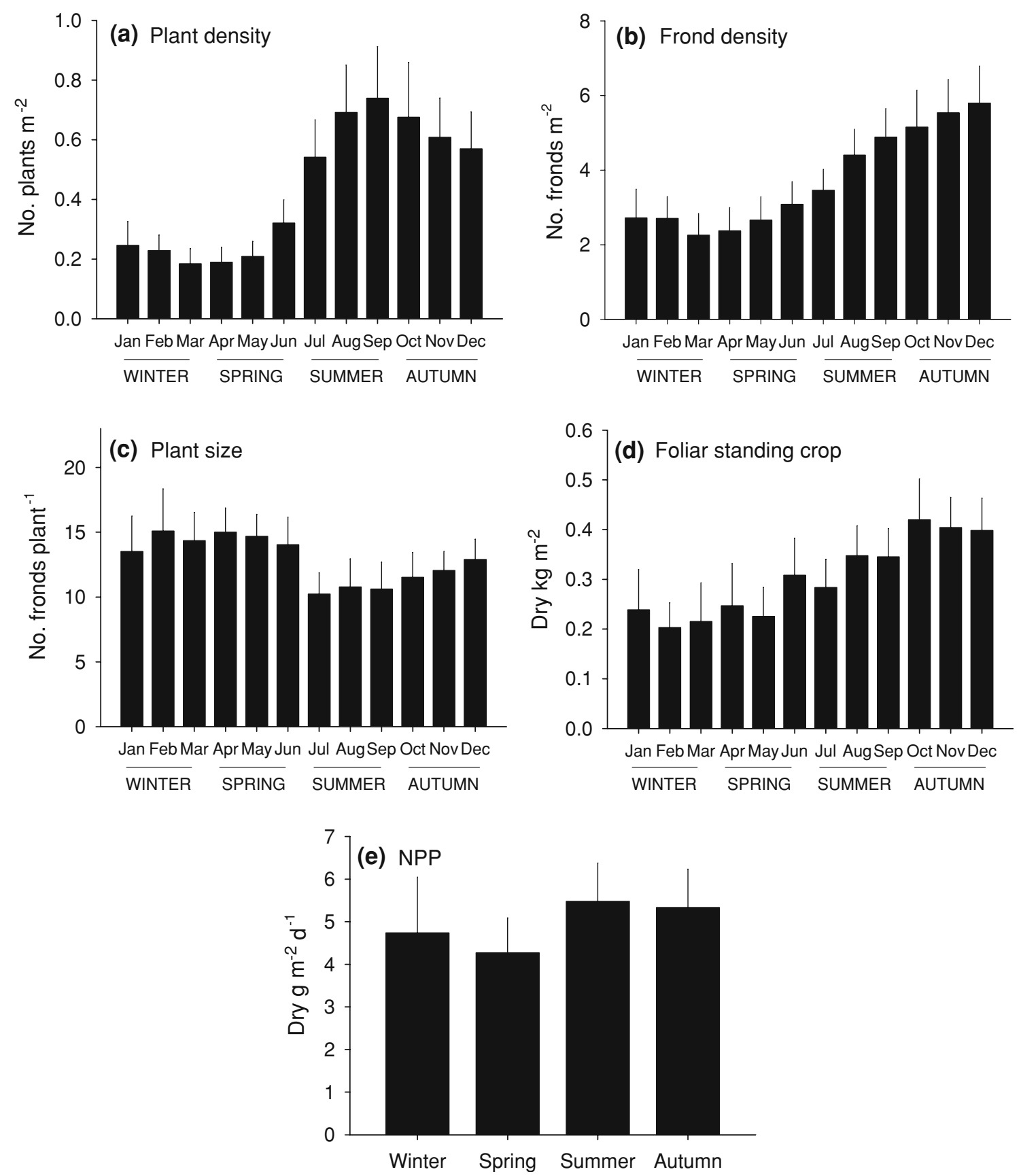

Fig. 1 Monthly values for a the density of plants $>1 \mathrm{~m}$ tall, $\mathbf{b}$ plant size as indicated by the number of fronds $>1 \mathrm{~m}$ tall per plant, $\mathbf{c}$ the density of fronds $>1 \mathrm{~m}$ tall, and $\mathbf{d}$ foliar standing crop. Seasonal

much better estimator of FSC than plants as fronds explained nearly $2 \frac{1}{2}$ times more of the observed variability in FSC than plants $\left(r^{2}=0.79\right.$ vs. 0.34$)$.

The usefulness of plant density in estimating seasonal NPP varied greatly with the time of year (Fig. 3a). Plant density explained a relatively large amount of variability in NPP in the winter and autumn (i.e., 75-94\%), and a much small amount variability in NPP during spring and summer (i.e., 29-57\%). By comparison, the relationship between values for net primary production are shown in e. Data represent means $(+\mathrm{SE})$ calculated from three sites for the period January 2003 through December 2008

frond density and seasonal NPP was much more constant throughout the year with $\mathrm{r}^{2}$ values ranging between 0.6 and 0.9 (Fig. 3b).

Plant density was a relatively poor estimator of annual NPP throughout most of the year. The relationship between NPP for a given year and the density of plants in a given month of that year steadily deteriorated over the course of the year from a high $r^{2}$ value of 0.65 in February to a low of 0.18 in October and November (Fig. 4a). In contrast, the 

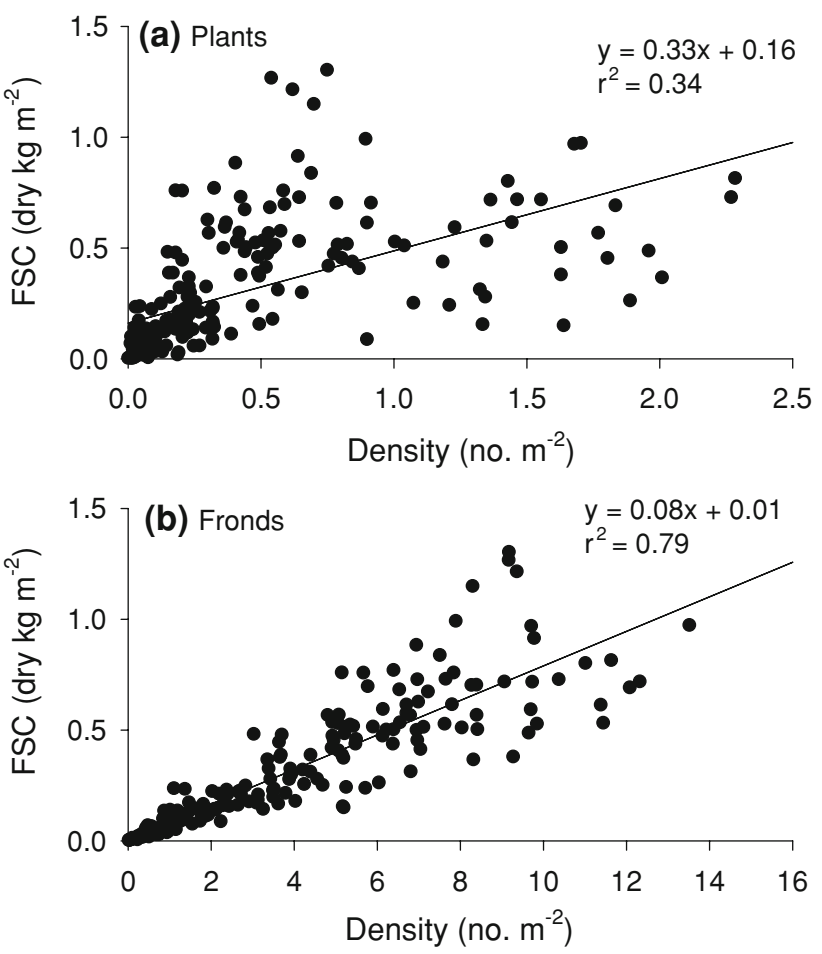

Fig. 2 The relationship between density and foliar standing crop (FSC) for a Macrocystis pyrifera plants and b Macrocystis pyrifera fronds. Data represent monthly values from three sites for the period January 2003 through December 2008

density of fronds provided a relatively good estimate of annual NPP, particularly when measured in June, July, or August when it explained a remarkable $70-81 \%$ of the variability in annual NPP (Fig. 4b).

The equations for the linear relationships between frond density versus seasonal NPP and between frond density versus annual NPP for each month are given in Table 1.

\section{Discussion}

The data used in this study encompassed substantial spatial (among sites) and temporal (within and among years) variation in $M$. pyrifera plant density, frond density, FSC and NPP (Reed et al. 2008). As such we believe that the relationships that we found among these variables are relatively robust and can be used to estimate FSC and NPP of $M$. pyrifera from a wide range of population densities. Our finding of consistently higher $r^{2}$ values when using fronds as a predictor of FSC and NPP argues that estimates of M. pyrifera FSC and NPP derived from measurements of population density should be based on densities of fronds rather than densities of plants.

That the density of fronds consistently provided a better estimate of NPP than the density of plants resulted from frond density being much more strongly correlated to FSC
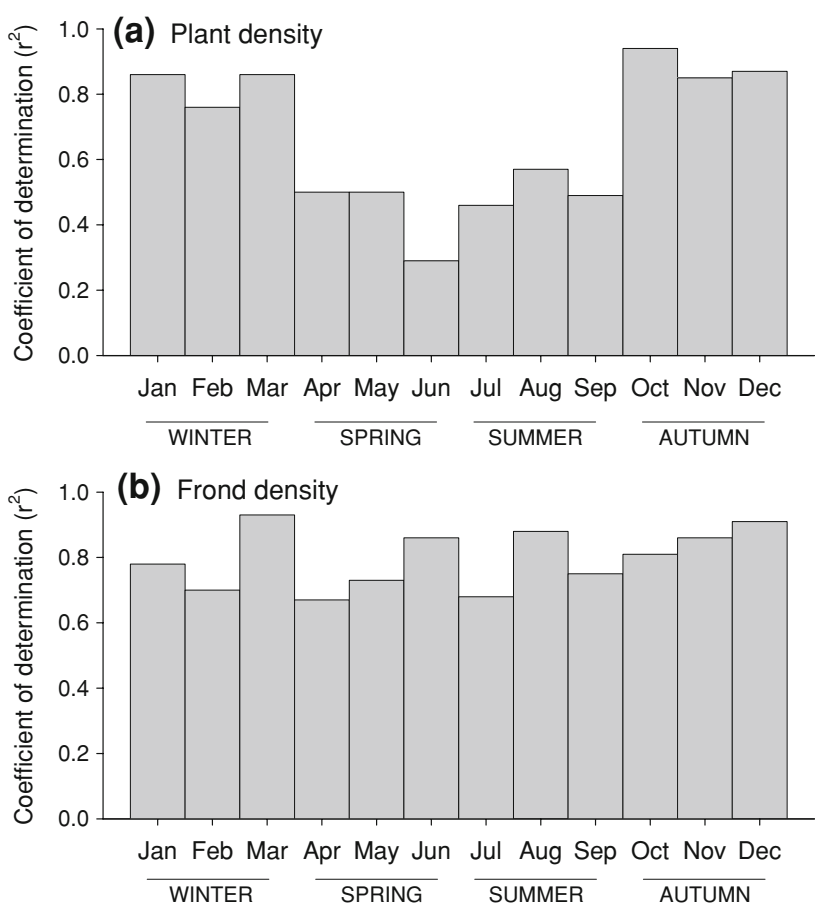

Fig. 3 Adjusted coefficients of determination $\left(r^{2}\right)$ for the relationship between NPP for a particular season of the year and a the density of plants during each month of that season, and $\mathbf{b}$ the density of fronds during each month of that season. Data represent monthly values from three sites for the period January 2003 through December 2008. $N=18$ for all months except Jan and Oct where $N=15 . P<0.02$ for all months for plants and $P<0.0001$ for all months for fronds

than plant density. This is not surprising given the high variation that exists in the size of $M$. pyrifera plants relative to the size of M. pyrifera fronds. In our study, plant size (as estimated by the summed length of all fronds) ranged from 1 to $1,435 \mathrm{~m}$, with the average plant size ranging from about 4 to $462 \mathrm{~m}$ depending on sampling date. By comparison, frond size in our study (as estimated by length) ranged from 1 to $32 \mathrm{~m}$ with the average frond size ranging from about 4 to $21 \mathrm{~m}$. Such variation in frond length would be expected to result in a similar variation in frond mass as length and mass are closely correlated (Attwood et al. 1991; Rassweiler et al. 2008). Despite this variation in frond mass, the density of fronds $>1 \mathrm{~m}$ tall still accounted for nearly $80 \%$ of the variation that we observed in FSC. The robustness of this finding indicates that the density of fronds $>1 \mathrm{~m}$ tall is likely to give a good estimate of the standing biomass of $M$. pyrifera in most regions provided that estimates of frond density are based on a sample size that adequately characterizes the population of interest.

The morphology of Macrocystis fronds is known to differ among regions within a species and among species within the genus (Neushul 1971; Gerard and Kirkman 1984; North 1994). Consequently the specific relationship between frond density and standing crop in Macrocystis is 


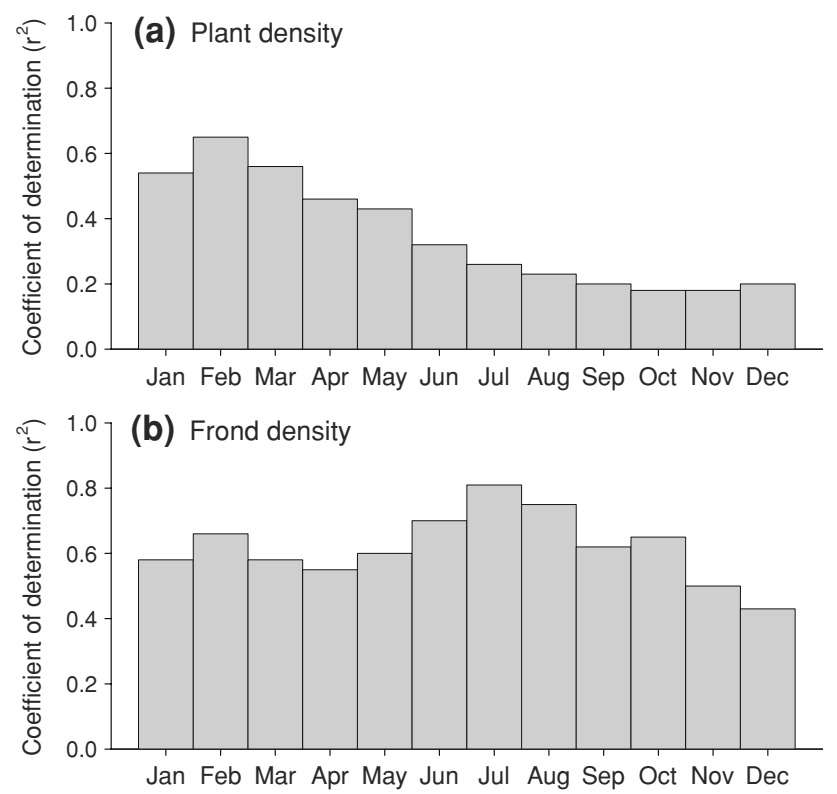

Fig. 4 Adjusted coefficients of determination $\left(r^{2}\right)$ for the relationship between annual NPP and a the density of plants during each month of the year, and $\mathbf{b}$ the density of fronds during each month of the year. Data represent monthly values from three sites for the period January 2003 through December 2008. $N=18$ for all months except Jan and Oct where $N=15$. In the case of plants, $P<0.05$ for all months except October where $P=0.06 . P<0.002$ for all months for fronds

likely to differ among populations and/or species of Macrocystis whose fronds differ in morphology. M. pyrifera fronds in Santa Barbara and elsewhere in California generally consist of a cylindrical stipe to which corrugated leaf-like blades (lamina) are attached via gas bladders (pneumatocyst) at intervals (nodes) that progressively decrease in length from the holdfast upwards to the sea surface (author's personal observations). This morphology is characteristic of the attached corrugated blade form of the species found in other regions of the world (Kain 1982; North 1994). Evidence from California indicates that the morphology of full-grown fronds does not change appreciably with depth as the number of blades (which constitute the majority of the frond's mass) on fronds growing at different depths is approximately the same (Clendenning 1963). As such, the relationships between frond density and standing crop that we derived for M. pyrifera for our study sites near Santa Barbara (Table 1) are likely to apply generally to the attached corrugated blade form of the species in other regions.

Estimating NPP over relatively short intervals such as seasons may serve many purposes and can be useful to a variety of ecological studies. Our results show that data on frond density collected during most months of the year provide a relatively good estimate of NPP by $M$. pyrifera for the season that the data were collected. Our finding that measurements of frond density made toward the end of a
Table 1 Linear equations for the monthly relationships between: (a) Macrocystis pyrifera frond density (no. $\mathrm{m}^{-2}$ ) for a given month versus seasonal NPP ( $g$ dry mass $\mathrm{m}^{-2}$ day $^{-1}$ ) for each month of the year, and (b) Macrocystis pyrifera frond density for a given month versus annual NPP (kg dry mass $\mathrm{m}^{-2}$ year $^{-1}$ ) for each month of the year

\section{(a) Equation}

Mean daily NPP during winter $=1.92$ (January frond density)

Mean daily NPP during winter $=1.88$ (February frond density)

Mean daily NPP during winter $=2.18$ (March frond density)

Mean daily NPP during spring $=1.08$ (April frond density) +2

Mean daily NPP during spring $=1.12$ (May frond density) +1

Mean daily NPP during spring $=1.26$ (June frond density)

Mean daily NPP during summer $=1.33$ (July frond density) +1

Mean daily NPP during summer $=1.22$ (August frond density)

Mean daily NPP during summer $=1.02$ (September frond density)

Mean daily NPP during autumn $=0.95$ (October frond density)

Mean daily NPP during autumn $=0.93$ (November frond density)

Mean daily NPP during autumn $=0.87$ (December frond density)

(b) Equation

Annual NPP $=0.32$ (January frond density) +0.911

Annual NPP $=0.37$ (February frond density) +0.787

Annual NPP $=0.36$ (March frond density) +0.994

Annual NPP $=0.33$ (April frond density) +1.034

Annual NPP $=0.34$ (May frond density) +0.906

Annual NPP $=0.38$ (June frond density) +0.645

Annual NPP $=0.44$ (July frond density) +0.301

Annual NPP $=0.34$ (August frond density) +0.314

Annual NPP $=0.28$ (September frond density) +0.428

Annual NPP $=0.27$ (October frond density) +0.364

Annual NPP $=0.22$ (November frond density) +0.591

Annual NPP $=0.18$ (December frond density) +0.738

Intercepts for all estimates of NPP are rounded to the nearest gram

season generally provided better estimates of NPP than did measurements made at the beginning of a season indicates that the timing of data collection within a season should be considered when devising a sampling plan for estimating seasonal NPP by M. pyrifera.

Annual NPP is dependent on the standing crop at the beginning of the growth year and the rate of change in the standing crop during the year arising from growth, recruitment and mortality. In the case of $M$. pyrifera the relationship between the density of fronds in a given month and annual NPP is sure to differ between populations in the northern and southern hemispheres given the 6-month offset in seasons. Even within hemispheres, however, the timing of $M$. pyrifera growth, recruitment and mortality are known to vary with latitude (Kain 1989; Brown et al. 1997). As a result, specific relationships between frond density and annual NPP will need to be tailored to regionalspecific patterns in these demographic processes. The linear relationships between monthly frond density and 
annual NPP that we derived using data from three populations of Santa Barbara are likely to be applicable to M. pyrifera populations throughout California because seasonality in recruitment, growth and mortality is similar throughout this region (Gerard 1976; Reed and Foster 1984; Graham et al. 1997; Reed et al. 2008).

There is considerable interest in understanding regional and global patterns and drivers of NPP, and the use of commonly collected data to estimate NPP (such as those that we describe here for $M$. pyrifera) makes assessments of NPP at broader spatial scales more tractable. In the case of $M$. pyrifera, the strong relationship between frond density and FSC is key to the usefulness of frond density as a predictor of NPP. It is reasonable to suppose that other metrics that reflect FSC in $M$. pyrifera might also be good proxies of annual NPP, particularly if measured in summer. One such metric may be the area at the sea surface covered by $M$. pyrifera fronds, which extend through the water column and form a dense floating canopy at the air-water interface. Canopy derived estimates of biomass and NPP of giant kelp may be particularly well-suited for large-scale spatial analyses because surface canopy area has the added benefit of being easily assessed remotely from above using aerial or satellite platforms (Jensen et al. 1980; Deysher 1993).

There is considerable interest and concern regarding the extent to which patterns of primary production are being altered by global and regional environmental change. Developing easy to apply methods for assessing changes in biomass and production, such as those reported here, will serve to improve our understanding of the patterns, causes and consequences of changing ecosystems. When employed over the long-term such methods should improve our ability to distinguish directional changes from inherent natural variability, thereby aiding in the development of strategies aimed at preventing and/or mitigating these changes.

Acknowledgments We thank M. Anghera, B. Evans, S. Harrer, B. Mardian, C. Nelson and numerous others for their tireless efforts in data collection and data management. This material is based on support by the U.S. National Science Foundation's Long-Term Ecological Research Program under grant numbers OCE 9982105 and OCE 0620276.

Open Access This article is distributed under the terms of the Creative Commons Attribution Noncommercial License which permits any noncommercial use, distribution, and reproduction in any medium, provided the original author(s) and source are credited.

\section{References}

Alongi DM (1998) Coastal ecosystem processes. CRC Press, Boca Raton

Attwood CG, Lucas MI, Probyn TA, McQuaid CD, Fielding PJ (1991) Production and standing stocks of the kelp Macrocystis laevis Hay at the Prince Edwards Islands, Subantarctic. Polar Biol 11:129-133

Brown MT, Nyman MA, Keoph JA (1997) Seasonal growth of the giant kelp Macrocystis pyrifera in New Zealand. Mar Biol 129:417-424

Clendenning KA (1963) Photosynthesis and growth in Macrocystis pyrifera. Proc Int Seaweed Symp 4:55-65

Dayton PK, Tegner MJ, Edwards PB, Riser KL (1999) Temporal and spatial scales of kelp demography: the role of oceanographic climate. Ecol Monogr 69:219-250

Deysher LE (1993) Evaluation of remote-sensing techniques for monitoring giant-kelp populations. Hydrobiologia 261:307-312

Edwards MS (2004) Estimating scale-dependency in disturbance impacts: El Niños and giant kelp forests in the northeast Pacific. Oecologia 138:436-447

Gerard VA (1976) Some aspects of material dynamics and energy flow in a kelp forest in Monterey Bay, California. Dissertation, University of California Santa Cruz

Gerard VA, Kirkman H (1984) Ecological observations on a branched, loose-lying form of Macrocystis pyrifera (L) C. Agardh in New Zealand. Bot Mar 27:105-109

Graham MH, Harrold C, Lisin S, Light K, Watanabe JM, Foster MS (1997) Population dynamics of giant kelp Macrocystis pyrifera along a wave exposure gradient. Mar Ecol Prog Ser 148:269-279

Graham MH, Vasquez JA, Buschmann AH (2007) Global ecology of the giant kelp Macrocystis: from ecotypes to ecosystems. Oceanogr Mar Biol Ann Rev 45:39-88

Jensen JR, Estes JE, Tinney L (1980) Remote-sensing techniques for kelp surveys. Photogramm Eng Remote Sens 46:743-755

Kain JM (1982) Morphology and growth of the giant kelp Macrocystis pyrifera in New Zealand and California. Mar Biol 67:143-157

Kain JM (1989) The seasons in the subtidal. Br Phycol J 24:203-215

Legendre P, Legendre L (1998) Numerical ecology, 2nd English edn. Elsevier, Amsterdam

Leigh EG, Paine RT, Quinn JF, Suchanek TH (1987) Wave energy and intertidal productivity. Proc Natl Acad Sci USA 84:13141318

Mann KH (1973) Seaweeds: their productivity and strategy for growth. Science 182:975-981

Mann KH (2000) Ecology of coastal waters. Blackwell, Maldin

Melillo JM, McGuire AD, Kicklighter DW, Moore B III, Vorosmarty CJ, Schloss AL (1993) Global climate change and terrestrial net primary production. Nature 363:234-240

Neushul M (1971) The species of Macrocystis. In: North WJ (ed) The biology of giant kelp beds (Macrocystis) in California. Beihefte Zur Nova Hedwigia, Verlag Von J. Cramer, Lehre, pp 211-223

North WJ (1994) Review of Macrocystis biology. In: Akatsuka L (ed) Biology of economic algae. SPB Academic Publishing, The Hague, pp 447-527

Rassweiler A, Arkema KK, Reed DC, Brzezinski MA, Zimmerman RC (2008) Net primary production, growth and standing crop of Macrocystis pyrifera in southern California. Ecology 89:2068

Reed DC, Foster MS (1984) The effects of canopy shading on algal recruitment and growth in a giant kelp (Macrocystis pyrifera) forest. Ecology 65:937-948

Reed DC, Rassweiler A, Arkema KK (2008) Biomass rather than growth determines net primary production by giant kelp. Ecology 89:2493-2505

Schneider B, Bopp L, Gehlen M, Segschneider J, Frolicher TL, Cadule P, Friedlingstein P, Doney SC, Behrenfeld MJ, Joos F (2008) Climate-induced interannual variability of marine primary and export production in three global coupled climate carbon cycle models. Biogeosciences 5:597-614

Sokal RR, Rohlf FJ (1995) Biometry: the principles and practice of statistics in biological research. 3rd edn. W.H. Freeman and Co., New York 